\title{
Fernando Calderón Gutiérrez (coord.), La protesta social en América Latina. Cuaderno de Prospectiva Política 1
}

$\mathrm{L}$

Protesta Social en América Latina es el primer cuaderno de perspectiva política, una iniciativa del Proyecto de Análisis Político y Escenarios Prospectivos (PAPEP), del Buró Regional para América Latina y el Caribe del Programa de las Naciones Unidas para el Desarrollo (PNUD). La colección a la que pertenece esta obra parte del análisis del proceso de revaloración de la política que vivió la región en la última década; profundiza en sus características y revisa, en el primer número, su vinculación con la gestión del conflicto social; en el segundo número, la gestión de la crisis económica global; en el tercero, la emergencia de distintos procesos de cambio sociopolítico en la región, y en el cuarto, las características y orientaciones del liderazgo político que lo impulsó, lo sustenta y lo proyecta. Todos estos cuadernos apuntan a fortalecer el ejercicio de la política democrática.

La Protesta Social en América Latina presenta los resultados de una investigación del PAPEP-PNUD en torno a los imaginarios del conflicto social latinoamericano, según fueron narrados por 54 periódicos de la prensa escrita en 17 países de la región ${ }^{1}$ en un periodo de once meses que va de octubre de 2009 a septiembre de 2010.

Todas las noticias referentes a conflictos sociales ${ }^{2}$ publicadas en 54 periódicos fueron recopiladas y analizadas en torno a cuatro categorías de

1 Argentina, Bolivia, Brasil, Chile, Colombia, Costa Rica, Ecuador, El Salvador, Guatemala, Honduras, México, Panamá, Paraguay, Perú, República Dominicana, Uruguay y Venezuela.

2 Entendidos como procesos de interacción contenciosa entre actores sociales e instituciones, movilizados con diversos grados de organización y que actúan de manera colectiva de 
análisis: campos del conflicto, conflictividad, niveles de radicalización y orientación política del gobierno hacia el conflicto. Además de dichas categorías, se consideraron variables como el tipo de conflicto, los actores dentro del conflicto y las regiones del conflicto, entre otras.

El libro abre con un capítulo conceptual en torno a la política constructivista entendida como el mejor recurso para procesar conflictos. En el segundo capítulo se realiza un balance de la crisis global en las economías centrales y los conflictos que ésta suscita. El capítulo tres trata brevemente los conflictos históricos en América Latina, como parámetro para comprender los conflictos actuales. El capítulo cuatro se refiere a la dinámica general del conflicto en la región, mientras que los capítulos quinto, sexto y séptimo se concentran en analizar los tres principales campos de conflictividad detectados en el análisis: reproducción social, institucional y cultural. El capítulo ocho trata de los conflictos en la red y del uso que los actores y movimientos sociales hacen de ella. El libro concluye con la construcción de escenarios prospectivos de conflicto basados en la proyección de las principales tendencias empíricas registradas, así como en estudios de prospectivas económicas de la región.

Es importante mencionar que, a pesar del título, la protesta social como manifestación de la sociedad civil organizada no es en realidad el actor central del libro, sino el conflicto como proceso necesario para que la democracia avance. No presenta un análisis a fondo de la protesta social en América Latina . De hecho, el actor movimiento social está ausente en él, así como otros actores sociales que históricamente han estelarizado procesos de lucha. En su lugar, el libro se concentra en el conflicto como detonante de la democracia, y lo revisa desde categorías generales de su manifestación y de su procesamiento por parte de los estados.

El punto de partida para los autores es entender la democracia como un orden donde el conflicto social, como dato de la realidad latinoamericana, es parte indispensable de los procesos de cambio. El conflicto en este sentido encierra potenciales positivos de transformación; es la ausencia de capacidades para gestionar los conflictos, ya sea del Estado o de la sociedad misma, lo que lleva a su escalamiento en la protesta, a su radicalización o a la respuesta violenta para contenerlo y negarlo. Es la falta de marcos institucionales que no ofrecen plataformas de diálogo y negociación lo que hace del conflicto una situación de estancamiento para la democracia.

acuerdo con expectativas de mejora, de defensa de la situación preexistente o proponiendo un contraproyecto social 
El constructivismo político es la clave que proponen los autores para abordar la gestión del conflicto en América Latina, para lo cual se necesitan tanto capacidades político-institucionales, como espacios de diálogo y una sociedad propositiva. En el constructivismo político, la política es vista como un sistema de expectativas y de reconocimientos recíprocos, en el que se establecen normas de reciprocidad en espacios de deliberación en los cuales se redefinen identidades sociales y políticas en conflicto. El constructivismo político implica interacción y reconocimiento del otro. Es lo opuesto a la búsqueda de hegemonía dentro de un sistema de opciones finales en el cual el otro es un enemigo a ser derrotado. En este sentido el libro no es únicamente una apuesta de los autores sino del PNUD mismo para revisar el procesamiento de los conflictos a lo largo de sus cuadernos sobre gobernabilidad.

Los medios de comunicación son el elemento de donde se recogen los datos para el estudio, con la consideración de que éstos reconfiguran constantemente el conflicto y sus dimensiones, en tanto fuentes de poder que construyen significados e imaginarios públicos así como espacios donde el conflicto se decide o se interpreta. También elaboran narrativas e imaginarios colectivos cuando aportan información sobre el conflicto, interpretándolo.

Los conflictos revisados tienen como ingrediente contextual la globalización como orden mundial y el neoliberalismo como marco económico, en cuya decisión de implementación se excluyó la participación ciudadana, lo cual dio lugar a crisis concretas en los ámbitos de la reproducción social, la cultura y la legitimidad institucional. La globalización entonces es un dínamo generador de conflictividad, y el capítulo dos del libro realiza un balance de la crisis global en las economías centrales y los conflictos que ella suscita, concentrándose en países del norte y en la emergencia, dentro del mismo contexto global, de los BRICS. ${ }^{3}$ Este capítulo hace una revisión sintética de los choques sociales que se han dado en las sociedades civiles y entre éstas y las cúpulas empresariales o gobernantes al ser excluidas de las direcciones económicas y políticas de sus países. Estos conflictos, aún en boga, servirían para entender mejor los actuales conflictos en los regímenes democráticos de América Latina, si fueran incorporados en el análisis de los capítulos subsecuentes. Sin embargo, las categorías de análisis que se emplean en el libro, y las diferentes variables, no se introducen hasta el tercer capítulo, lo que impide una lectura sistemática desde el inicio que permita elaborar un guión comparativo a lo largo del texto.

3 Nombre que se da a las economías emergentes: Brasil, Rusia, India y Sudáfrica. 
El capítulo tres hace una revisión histórica, bastante sintética, pero también bastante completa en su marco histórico y contextual, de las tendencias políticas que han existido en América Latina para procesar, o intentar gestionar, el conflicto por parte de los gobiernos. En América Latina las elites de poder han sido más dominantes que dirigentes; han procesado los conflictos con ensayos diferentes de políticas para lograr la gobernabilidad. El libro ofrece un buen panorama de estos ensayos, sus orígenes y sobre todo sus consecuencias en la estructura de las diferentes formas de protesta que se detectan en la región. Como formas de gobierno, tuvieron un papel determinante en moldear la sociedad y sus estrategias para posicionar el conflicto, como el populismo creador de nacionalismo, las dictaduras y su debilidad institucional para regular y organizar el conflicto, y la vida social y la democratización diferenciada que dio lugar a distintas relaciones gobierno-sociedad para el procesamiento de conflictos.

Estas formas de gobierno se reconfiguran en distintas formas de procesar los conflictos emanados de la sociedad, después de la transición aceptada como consolidada a la democracia. Los autores llaman a estas distintas formas "orientaciones políticas" y las constituyen como categorías de análisis, aunque no queda claro cuáles orientaciones políticas predominan según el tipo de régimen anterior al democrático en los diferentes países, lo cual aportaría al hilado del texto para contextualizar las diferentes variables de análisis que se presentan posteriormente.

Las orientaciones políticas que los autores consideran como categorías de análisis, de acuerdo con la capacidad institucional que se configuró en los gobiernos para lidiar con las crisis políticas y económicas contemporáneas son: modernización conservadora, reformismo práctico, neodesarrollismo indigenista, y nacional popular. Estas formas de orientación política se combinan aunque, por lo general, una tiende a dominar.

En el capítulo cuarto se introducen los demás elementos del análisis para los 2,318 conflictos que se detectaron y procesaron en la base de datos que sustenta el libro. Destacan entre éstos los campos del conflicto, es decir, los tipos de demandas y luchas que se publicaron en la prensa durante el periodo de estudio. Esta tipología constituye un aporte importante de los autores para entender las principales causas de conflictos percibidas por la sociedad y que en su mayoría ( $80 \%$ ) se dirigen al Estado como actor demandado. En tres campos de conflicto se engloba el total de las luchas revisadas: conflictos por reproducción social que comprenden todos aquellos orientados a lograr una mejor calidad de vida; los conflictos institucionales, es decir, aquellos que buscan mayor eficacia y legitimidad por parte de las instituciones del Estado o ante el Estado, y los conflictos culturales dirigidos a cambiar los modos de vida. 
Otra categoría de análisis generada por los autores es la relación del Estado con la sociedad para el procesamiento de conflictos, lo cual conduce al análisis del tipo de respuesta que el Estado tiene para dar cauce a las demandas ciudadanas, independientemente de sus contenidos. Los autores distinguen estados sólidos que articulan marcos institucionales para manejar importantes niveles de conflictividad de manera consensual (como el caso de Uruguay); estados con medianas e irregulares capacidades para procesar los conflictos, con una lógica negociadora a mediante mecanismos semiinformales de arbitraje y negociación, en los que se dan conflictos medios a importantes (Brasil); sociedades con alta capacidad e intensa tradición de movilización ante un Estado con capacidades débiles e ineficientes para procesar los conflictos en los marcos institucionales (Perú y Bolivia), y estados fuertes con sociedades con niveles relativamente bajos de acción colectiva y protesta (Costa Rica, Chile).

El intento con esta categoría generalizadora de los procesos entre Estado y sociedad es interesante y permite aproximarse a entender el avance hacia el constructivismo político en los diferentes países de la región, pero a ello no contribuye el análisis general que posteriormente se presenta, en cuanto se arroja la información al terreno de lectura y se diluye el análisis en una multiplicidad de variables.

El capítulo cinco, con el análisis concreto de los conflictos por reproducción social (los más numerosos con 1097 casos), referidos a las capacidades de una sociedad para continuarse o cambiar a lo largo del tiempo, asociada a umbrales básicos de calidad de vida, al concepto de bienestar y de vida digna como condición para la libertad es el mejor logrado, pues incorpora un buen marco teórico de conceptos y posicionamientos que permite contextualizar el análisis de este campo de conflicto con la desigualdad social como factor detonante de estas demandas. El análisis de este capítulo y de los subsecuentes alrededor de cada campo de conflicto toma la temperatura de cada país en materia de percepción de la desigualdad (con el uso de datos del latinobarómetro), comparándolas con los datos duros arrojados por las estadísticas. Queda como gran faltante en este capítulo establecer el cruce entre desigualdad en el ingreso y el número de conflictos que se presentan por país, datos que se encuentran separados en el análisis. No obstante, el capítulo permite una buena discusión con los autores y una fluidez en la lectura.

El capítulo sexto se refiere a los conflictos institucionales (874 casos detectados), que son los que tienen el potencial de trascender la defensa de derechos puntuales y de orientarse hacia la reestructuración del sistema de reglas de distribución y ejercicio del poder en un sentido más amplio. Aquí también se presenta un marco teórico y conceptual completo sobre 
el origen y las potenciales causas de este tipo de conflicto en la región. Sin embargo, en el desarrollo analítico se formulan hipótesis que, a partir de la información recopilada, siguen quedando sin posibilidad de ser respondidas, y abren al lector cuestionamientos que sin duda se pueden traducir en posteriores preguntas de investigación con alta relevancia en materia de gobernabilidad para la región.

El capítulo siete, de conflictos culturales, contextualiza este tipo de lucha en las diferencias socioeconómicas y la historia de dominación de los países de la región. Ofrece explicaciones coherentes a la interpretación de los datos y por categoría de análisis. Aquí también la recopilación teórica de las aproximaciones hacia los movimientos culturales, de índole identitario, étnico, generacional o intelectual, es completa. Este conflicto, aunque el menos numeroso (374) es el de mayor alcance sistémico, en tanto que, con el uso de las nuevas tecnologías de la información y el conocimiento, se enlaza con movimientos similares a nivel mundial.

Las gráficas que se presentan en los capítulos analíticos de los campos de conflicto son homogéneas y esto facilita las comparaciones consistentes que el lector considere pertinente elaborar, para llegar a conclusiones propias o incluso preguntas nuevas de investigación para las que el libro ofrece un buen punto documental de partida.

La multiplicidad de variables que se arrojan a lo largo del texto permite hacer del mismo un buen documento de consulta para la investigación más específica. Sin embargo, no hace del mismo un estudio que permita entender los detonantes y los elementos de la protesta social en América Latina. Más aún porque no se documenta la solución de 74\% de los conflictos que se siguieron. Esto, como bien lo explica el libro mismo, se relaciona con la falta de noticias en la prensa. Sin embargo, el hecho de no haber podido documentar este final o epílogo de los conflictos introduce un sesgo analítico en detrimento de las conclusiones de la situación actual en materia de constructivismo político, pues el proceso queda incompleto y por tanto también las conclusiones que deben matizarse en tanto que no se sabe si hubo una negociación, o una apertura institucional para dar fin a los conflictos. Esto también debilita la categoría de orientaciones políticas cuya existencia está sustentada en la respuesta del Estado al conflicto.

La agrupación de los países por orientación política o por región (andina, cono sur, Centroamérica), obliga a que el lector interesado en un país en particular se remita a las fuentes bibliográficas, lo que indudablemente sirve como fuente generadora de mayor conocimiento, aunque el análisis que se hace de la información dentro del libro mismo es muy general y a menudo se limita a una descripción del contenido gráfico. 
La protesta social en América Latina es un buen documento de la situación actual en materia de los campos de conflicto más relevantes en América Latina. Realiza análisis generales que si bien no ofrecen particular atención a cada país, sí dan un panorama importante de la relación entre tipos de sociedad, motivos de los conflictos y orientaciones políticas del Estado para gestionarlos. Sin embargo, debido a cuestiones relativas a la base de datos empleada, no permite realmente entender los procesos de gestión de conflictos ante los gobiernos. Ofrece un buen panorama de las tendencias de los conflictos iniciados por la sociedad, pero no se trata de un análisis integral ni integrado sobre el estado actual del conflicto. Uno de los talones de Aquiles del libro estriba en que la prensa escrita que no siempre refiere el final de los conflictos, como bien lo marcan los autores en el libro, pero además en que no toma en cuenta las nuevas tecnologías de información y comunicación, que son los medios vivos donde también se dan las batallas. El último capítulo habla de estos medios como los campos en los que se construyen y se debaten gran número de conflictos, pero no se integra esta discusión al texto, lo que deja un hueco importante en el panorama. Las nuevas subjetividades culturales están cada vez más asociadas con los usos sociales de las nuevas tecnologías por lo que dejarlas al margen del análisis, considerarlas por separado, introduce un sesgo importante al análisis.

La conclusión a la que se arriba en todos los capítulos se relaciona con la necesidad de repensar el concepto mismo de la democracia, hacia una dimensión más deliberativa, plural y participativa. Tanto la democracia liberal como los nacionalismos típicos de América Latina han fracasado en el reconocimiento de la legitimidad de los actores sociales y de sus demandas, y tienden a imponer agendas públicas sin escuchar ni tomar en cuenta los problemas reales de las sociedades. Tal vez por eso los patrones de desigualdad que permean todos los conflictos, ya sea con actores de mercado, de gobierno o de la misma sociedad civil, se mantienen fuertes hasta la fecha.

Evidentemente, el reconocimiento de la interculturalidad de las sociedades latinoamericanas será un paso grande en el perfeccionamiento de las democracias de la región, lo que conducirá a niveles aceptables de gobernabilidad, pero ésta es una apuesta política que subyace en el libro como conclusión, no como una directriz constante del análisis.

Por último, el libro fija una serie de "escenarios de conflictividad social" hasta el 2015, que echan luz sobre aquellas tensiones aún latentes que pudieran aflorar en las democracias contemporáneas. Para el planteamiento de estos escenarios se introducen nuevas variables: clima social, que depen- 
de del tipo de factores que impactan en la mejora o deterioro de la calidad de vida, así como de sus tiempos y mecanismos; los acumuladores de tensión que se relacionan con la persistencia de un modelo de desarrollo excluyente (brechas sociales, participación, desigualdad económica), y los detonadores de tensión de largo plazo (desempleo masivo, hiperinflación, deterioro de servicios, corte de subsidios, fraudes electorales). A partir del análisis de este nuevo grupo de variables que se confunden con las empleadas en la primera parte del libro, los autores proyectan cuatro posibles escenarios de gestión del conflicto en América Latina.

El primer escenario se caracteriza por presentar climas sociales relativamente positivos y una importante capacidad de procesamiento de conflictos (Uruguay, Brasil, Costa Rica y Argentina); el segundo está caracterizado por un clima social positivo pero con baja capacidad de procesamiento de los conflictos por parte del Estado (Chile, Colombia y Paraguay); en el tercero se encuentran países que en la coyuntura actual tienen problemas generados por un clima social deteriorado y limitaciones gubernamentales para procesar los conflictos (Venezuela, Guatemala, México y Honduras); por último, en el escenario 4 se encuentran países con importantes capacidades de procesamiento de conflictos, pero con climas sociales de alta complejidad para desarrollar consenso y constancia en su interior (El Salvador, Bolivia, Ecuador, República Dominicana y Perú).

El marco de estos escenarios en el capítulo 9 ofrece una buena síntesis de los análisis que se presentan a lo largo del libro; condensa en unos cuantos párrafos las categorías que fueron más revisadas a lo largo del texto, y aborda las tendencias generales por grupo de país, aún si al revisar a cada uno en su contexto específico éste saliera considerablemente del escenario en el que está ubicado.

Finalmente el libro plantea que "el horizonte deseable, la situación ideal es aquella en la que existen, a la vez, conflictos sociales y capacidades institucionales y políticas para procesarlos". Lo contrario, afirman, es un Estado incapaz de asumir los desafíos que plantean los conflictos sociales.

Joaliné Pardo Núñez*

* Doctora en Ciencias Sociales con mención en Sociología por la Facultad Latinoamericana de Ciencias Sociales, sede académica de México 